\title{
Bob Jessop e a abordagem relacional-estratégica
}

\author{
Rodolfo Palazzo Dias ${ }^{1}$
}

Resumo: O presente artigo busca tratar do trabalho teórico do autor marxista Bob Jessop. Nossa análise consiste em verificar a forma com que o autor se apropriou de diversas noções formuladas por Nicos Poulantzas. Nossa proposta é que Jessop traz uma série de transformações epistemológicas, metodológicas e conceituais, em relação à obra poulantziana, que permite trabalharmos a noção de "abordagem relacional-estratégica" como uma perspectiva diferenciada dentro do marxismo. Para uma análise adequada do autor devemos retomar tanto a trajetória acadêmica deste, verificando quais influências existiram na sua formulação teórica, como também seu diálogo com outras perspectivas. Sobre esse segundo ponto acreditamos que o diálogo de Jessop com o institucionalismo esclarece quais foram as mudanças epistemológicas e metodológicas do autor em relação a Poulantzas. Por fim, faremos uma análise de alguns conceitos econômicos e políticos que Jessop utiliza em sua abordagem. Os conceitos de "forma-valor", "forma-Estado", "estratégia de acumulação" e "projeto hegemônico" são chaves na compreensão da forma diferenciada com que Jessop aborda tanto a relação entre economia e política, como a relação entre estrutura e agência.

Palavras-chave: Bob Jessop; abordagem relacional-estratégica; estruturalagência

${ }^{1}$ Graduado em Ciências Sociais pelo Instituto de Filosofia e Ciências Humanas da Unicamp. 
Abstract: The present article seeks to discuss the theoretical work of marxist writer Bob Jessop. Our analysis is related to the way the author took over various notions made by Nicos Poulantzas. Our proposal is that Jessop has epistemological, methodological and conceptual changes in relation to the work of Poulantzas, allowing us to work with the notion of "strategic-relational approach" as a distinct perspective in Marxism. For a proper analysis of the author, we must return both his academic career, verifying influences existed in his theory as well as his dialogue with other perspectives. On this second point we believe that the dialogue of Jessop with institutionalism explains what epistemological and methodological changes existed comparing with Poulantzas. Finally, we will review some concepts of economic and politics Jessop uses in his analysis. The concepts of "value-form", "state-form", "accumulation strategy" and "hegemony" are important in understanding the different way that Jessop discusses both the relationship between economics and politics as the relationship between structure and agency. Keywords: Bob Jessop; strategic-relational approach; structurelagency 


\section{Introdução: influências no trabalho de Bob Jessop}

Nosso artigo possui o intuito de apresentar o pensamento de Bob Jessop, autor chave no marxismo que trata da "abordagem relacionalestratégica do Estado". Em nosso trabalho destacamos principalmente dois autores; Nicos Poulantzas e o Bob Jessop. Poulantzas entra na discussão, pois é ele quem primeiro define uma concepção de Estado baseado na noção de poder relacional na perspectiva marxista; o conceito de Estado enquanto "condensação material de uma relação de forças entre classes e frações de classes" (POULANTZAS, 2000).

Porém, focamos nossa análise em Bob Jessop, autor que, além de se apropriar de diversas noções formuladas por Poulantzas, alterou a perspectiva epistemológica, metodológica e conceitual deste, permitindo uma análise da noção de abordagem relacional-estratégica como diferenciada dentro do marxismo.

Iniciamos nosso trabalho através de um resgate das questões não somente teóricas, mas também políticas e pessoais, que levaram Bob Jessop à construção de suas obras. Em entrevista à Mürekkep, Jessop (2002) trata de alguns fatos pessoais, como sua origem em uma família conservadora do interior da Inglaterra, e também a marginalidade que o marxismo sofria dentro da Universidade na qual se graduou, para destacar que seu contato com o marxismo surgiu somente quando iniciou a pós-graduação, em Cambridge.

Esse contato, segundo Jessop, foi muito intenso devido à própria circunstância histórica da época (1967-68), um período conturbado politicamente no mundo. Essas influências pessoais e políticas se refletiram no seu trabalho de Doutorado, aproximando-o da linha marxista. Dois autores foram fundamentais nessa aproximação: Antonio Gramsci e Louis Althusser. 
"Por um lado, com Gramsci apre(e)ndi a importância de uma visão ampla do Estado ("Lo Stato Integrale"), a importância da hegemonia política, moral e intelectual para a estabilidade dos Estados democráticos. Por outro, Althusser ensinou-me a importância de uma rigorosa teorização no movimento do abstracto ao concreto, do simples ao complexo, assim como me forneceu algumas luzes em torno da natureza do capitalismo como uma modalidade de produção e da necessidade de uma análise conjuntural." (JESSOP, 2002, p.6-7).

E essa influência dupla era sintetizada em um autor especifico:

"Por sua vez, estes dois teóricos marxistas surgem simultaneamente na obra de Nicos Poulantzas, o teórico grego que trabalhou o poder político $e$ as classes sociais nos Estados democráticos burgueses organizados em torno da luta pela hegemonia." (JESSOP, 2002, p.7)

\begin{abstract}
Além dessa grande influência teórica, Jessop em sua entrevista destaca a grande importância que o "Thatcherismo" teve na sua produção intelectual, principalmente nos anos 80:

"De facto, grande parte do trabalho que tenho desenvolvido tem sido moldado por uma constante tentativa em compreender a especificidade da crise da economia política britânica do pós-guerra e a importância da resposta do "Thatcherismo". É esta frequente dimensão política subterrânea do meu trabalho que proporciona a base do projecto intelectual que eu persegui durante anos e anos." (JESSOP, 2002, p.8)
\end{abstract}

Portanto, dentro de um debate político contextualizado pela ascensão do neoliberalismo na Inglaterra, e sob a influência teórica de Nicos Poulantzas, é que Jessop desenvolve suas obras e sua perspectiva analítica "estratégica-relacional". 


\section{Poulantzas e Jessop: semelhanças e divergências epistemológicas, metodológicas e conceituais}

Como já foi colocado acima, Poulanzas foi quem formulou primeiramente uma concepção de Estado baseada em uma perspectiva relacional de poder. Porém, essa formulação não estava presente em suas obras iniciais; essa perspectiva relacional surgiu enquanto uma influência foucautiana ${ }^{2}$, que o levou a um distanciamento de uma concepção regional de Estado (marca da obra "Poder político e classes sociais") e o levou a uma concepção relacional, marca de suas últimas obras.

Essa abordagem relacional é a que mais influencia Jessop:

"Poulantzas argumentou que o Estado é uma relação social exatamente no sentido do capital também ser uma relação social. Esta abordagem exclui qualquer tratamento do Estado tanto como um simples instrumento ou como um sujeito." ${ }^{\prime 3}$ (JESSOP, 1985, p.336-337).

Além de destacar essas vantagens analíticas, Jessop destaca dois aspectos do Estado que se tornam objetos de estudo na adoção dessa perspectiva; deve-se estudar o Estado enquanto instituição (a condensação material propriamente dita), e para isso a noção de "seletividade estrutural" é mobilizada nesse intuito; e também se deve analisar a luta de classes em si, os conflitos de classe que estão no Estado e vão além deste.

A questão da definição poulantziana de Estado é uma problemática que iria requerer um trabalho dedicado exclusivamente a esse tema, mobilizando um debate sobre a abordagem regional em contraposição a uma abordagem relacional (estudo das diferenças das obras iniciais e finais do autor). O que buscamos desenvolver em nosso trabalho é apenas a dimensão de Poulantzas que é apropriada por Jessop,

${ }^{2}$ Embora Poulantzas (2000) busque deixar claras as suas diferenças em relação ao Foucalt.

${ }^{3}$ As citações realizadas nesse artigo de textos em inglês foram traduzidas por nós. 
ou seja, a abordagem relacional do Estado. Embora Jessop adote uma perspectiva muito semelhante a de Poulantzas com relação à perspectiva relacional do Estado, as diferenças entre os dois autores são mais claras quando tratamos da questão do conceito de estratégia.

Estratégia é definida por Poulantzas (1974) no seguinte trecho:

"A articulação da determinação estrutural de classes e as posições de classe no seio de uma formação social, lugar de existência das conjunturas, requer conceitos particulares. Trata-se daquilo que chamarei de conceitos de estratégia, abrangendo principalmente os fenômenos de polarização $e$ de alianças de classes." (POULANTZAS, 1974, p.25)

Existem duas coisas que queremos destacar dessa definição de Poulantzas: estratégia não é um conceito em si, mas sim é um conjunto de conceitos com determinado papel dentro do método poulantziano; esse papel seria de tratar da dimensão do concreto.

O método desenvolvido por Poulantzas possui a preocupação de fazer uma mediação entre conceitos abstratos e a realidade concreta; a relação que existe entre as determinações estruturais de classe e a posição de classe na conjuntura, epistemologicamente, poderia ser colocada em termos de relação entre abstrato / concreto. Para a compreensão desse concreto, segundo Poulantzas, é necessário um conjunto de conceitos (bloco no poder, hegemonia, etc.), que seriam reunidos no conjunto chamado "conceitos de estratégia".

Quando pensamos o conceito de estratégia em Jessop devemos atentar para uma diferença epistemológica entre ele e Poulantzas. Enquanto este está principalmente preocupado com a relação concreto / abstrato, Jessop inclui a preocupação do simples / complexo. Como coloca Mahon (1991):

"No entanto, para Jessop, articulação envolve mais que o movimento do abstrato ao concreto: para desenvolver um quadro teórico adequado para o objetivo de descobrir causalidades históricas também se deve mover do simples ao complexo, articulando diferentes, porém comensuráveis, sistemas teóricos. Aqui Jessop rompe com Poulantzas na medida em que ele parece disposto a reconhecer a necessidade de incorporar outros sistemas 
teóricos se o objetivo é apreender o real-concreto em todas as suas multiplicidades de determinações." (MAHON, 1991, p.134-135)

Percebemos que Jessop não se opõe à reflexão de Poulantzas sobre abstrato / concreto; o que ele faz é inserir o debate do simples / complexo dentro de sua lógica epistemológica, inserção esta que, em sua entrevista, atribui às suas influências althusserianas, e não poulantzianas.

Essa diferença epistemológica levou a uma utilização metodológica completamente diferente do conceito de estratégia. Este conceito passou a ser entendido não apenas em sua dimensão concreta (enquanto prática política), mas também em sua dimensão complexa. Segundo Jessop (1985) a respeito dos conceitos vindos dessa teoria da estratégia:

"Eles podem ser usados para dissolver as leis abstratas, unitárias e essencializadas dos movimentos e necessidades do capital construídas pela lógica do capital em uma série de lógicas mais concretas e contingentes do capital. E eles podem ser usados para superar a tendência da análise teórica das classes em focar nas modalidades concretas das lutas sócioeconômicas de maneira a negligenciar a forma em favor do conteúdo." (JESSOP, 1985, p.344)

Em relação às lógicas do capital, existe a preocupação tanto de tornar concreta a discussão dessas lógicas como também de tornar mais complexo o entendimento destas (a própria idéia de formas de reprodução do capital é pensada no plural, ou seja, não existiria apenas uma forma de reprodução); e também o posicionamento do autor nega uma análise da luta de classes que utilize como variável explicativa apenas noções estruturais (conteúdo), ressaltando também a importância das instituições, das lutas políticas concretas (forma) dentro da análise.

Essa utilização metodológica diferenciada levou o autor a dar um novo significado para a noção de estratégia. Esta não é mais um conjunto de conceitos que se remete a uma dimensão de análise; Jessop desenvolve a idéia de uma abordagem teórica baseada na estratégia, o que ele chama 
de "strategic-relational approach" (JESSOP, 1985), abordagem esta que consegue transitar das noções abstratas e unitárias para problemas concretos e complexos, os quais possuem tanto a dimensão da sua forma como de seu conteúdo.

Essas diferenças ficam claras quando discutirmos os trabalhos conceituais que o autor desenvolveu. Primeiramente trabalharemos com o debate sobre institucionalismo produzido por Jessop; depois trataremos de conceitos chaves desenvolvidos pelo autor para trabalhar tanto com a política como com a economia em termos marxistas.

\section{Institucionalismo: uma abordagem estratégica-relacional}

Jessop, em seu texto "Institutional re(turns) and the strategic-relational approach", busca analisar o debate teórico realizado nas últimas décadas que busca revalorizar a importância das instituições políticas dentro da Ciência Política.

A forma que Jessop trata as perspectivas institucionalistas torna muito clara a importância tanto da relação abstrato / concreto, como também da relação simples / complexo na metodologia do autor.

Através de uma análise das formas como os autores de Ciência Política passaram a abordar esse "retorno" das instituições enquanto objetos relevantes (essas formas são separadas em abordagens temática, metodológica e ontológica), Jessop define tanto perigos como vantagens que essas abordagens possuem.

O principal perigo que Jessop destaca é a possibilidade de reificação e naturalização que tais abordagens podem levar; esse tipo de naturalização pode ser fruto da forma como o tipo de abordagem institucionalista percebe a importância das instituições.

Segundo o autor, as abordagens que vão além da temática, criam um conceito específico de instituição, e também estabelecem uma lógica especifica pela qual as instituições se relacionam com o resto da sociedade. Uma abordagem que não naturalize as instituições deve analisá-las com um nível de contextualização espaço-temporal, sendo esta contextualização o fator explicativo da relevância das instituições. 
Esta questão da contextualização da instituição levanta o problema da relação entre abstrato / concreto. Jessop define uma série de passos na análise das instituições:

"Mesmo nesses termos relativamente simples, fazer uma volta ao estudo das instituições requer um localização especifica dessas. Existem várias etapas envolvidas nisso. A primeira etapa é definir, localizar e tematizar instituições de modo a torná-las menos vagas e liminares. O próximo é entender como as instituições operam e são reproduzidas pelas ações rotineiras que 'produzem' ou executam as instituições. (...) As etapas seguintes em uma agenda de pesquisa devem incluir questões sobre consolidação institucional ou sobre governança institucional, ou seja, o governo das instituições, as relações interinstitucionais e o ambiente sistêmico. Finalmente, deve-se examinar questões de desenho institucional e implementação". (JESSOP, 2001, p.1221).

Percebemos que esse processo proposto por Jessop inicia-se em um trabalho abstrato de definição das instituições, e termina em uma análise de como a instituição se coloca concretamente. Essa lógica de partir do abstrato e chegar ao concreto, mais do que exigir uma contextualização espaço-temporal, também requer uma relação especifica entre estruturas e agentes sociais.

A partir desse ponto é que começa a se revelar a importância da relação simples / complexo dentro da metodologia de Jessop. Pretendendo dar conta da relação estrutura / agência, Jessop elabora a Figura 1 em seu artigo; nesta figura, percebemos a estrutura e a agência colocadas lado a lado, e através de uma relação entre as duas, aliadas à inserção dos fatores "estratégia" e "reflexividade", Jessop produz um debate que complexifica o problema das estruturas e da agência social. Enquanto que no início da linha de pensamento existe a oposição entre estruturas enquanto constrangimentos externos e indivíduos com vontade própria, a inter-relação entre os dois fatores leva a formulação de estruturas construídas socialmente e de agentes socializados; depois, mais uma inter-relação utilizando as noções de estratégia e reflexividade gerariam uma interpretação da relação estrutura / agência que Jessop (2001) define como: 
"Juntos, esses conceitos indicam que o escopo para a reorganização reflexiva das configurações estruturais é sujeita a estratégia seletiva inscrita estruturalmente (e, assim sendo, possui aspectos tanto de dependência da agência como de moldagem desta4)." (JESSOP, 2001, p.1224)

\section{Figura 1}

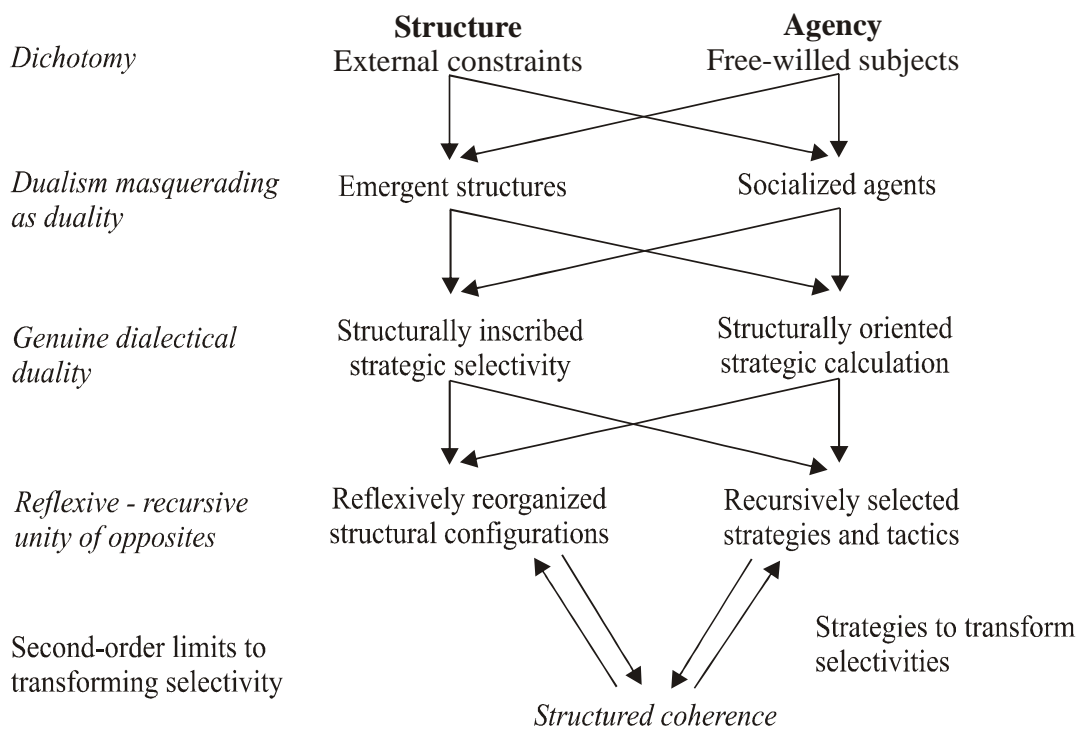

Fonte: Jessop, 2001.

Esse processo de complexificação também é observável no debate posterior feito por Jessop sobre como a questão espaço-temporal pode ser trabalhada pela abordagem estratégico-relacional. Enquanto sob a divisão inicial entre estrutura e agência o problema se coloca inicialmente como ou uma pura externalidade (espaço-tempo newtoniano) ou um voluntarismo (idealismo kantiano), a questão do espaço-tempo é relacionada entre si e também com as noções de estratégia e reflexividade, exposto em seu artigo com a Figura 2, e o leva à seguinte conclusão:

\footnotetext{
${ }^{4} \mathrm{O}$ trecho colocado entre parênteses no original está escrito: "and thus has path-dependent as well as path-shaping aspects".
} 
"Primeiro, a abordagem relacional-estratégica não postula estruturas abstratas, não localizadas e atemporais ou atividades totalmente rotineiras realizadas por 'reprodução cultural' ou atores habituados. Estruturas são inevitavelmente concretas, espacializadas e temporalizadas; e elas não tem sentido fora do contexto dos agentes específicos que possuem estratégias especificas - até se estas últimas são expressas no nível da consciência prática em vez de maneira explicita e reflexiva." (JESSOP, 2001, p.1228).

\section{Figura 2}

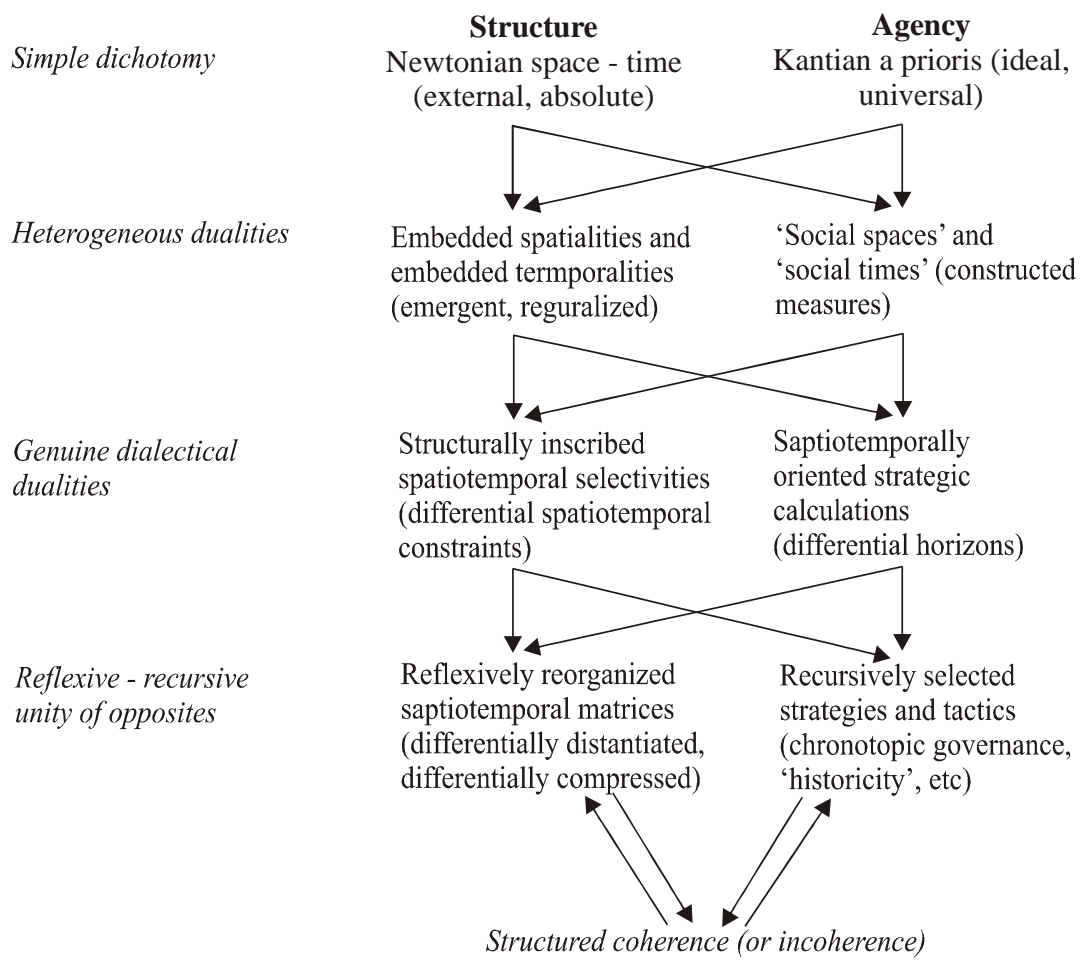

Fonte: Jessop, 2001. 
Portanto, para o SRA (strategic-relational approach), a dimensão espaço-temporal é fundamental na análise para o processo de contextualização da instituição dentro da realidade, além dos agentes e suas estratégias.

O que queríamos destacar nessa analise de Bob Jessop do instituicionalismo, era menos a maneira como esse autor define ou se enquadra dentro dessa corrente, mas mais como o autor faz esse tipo de analise; buscamos demonstrar que durante todo o processo de análise, as lógicas epistemológicas de abstrato / concreto e de simples / complexo fizeram parte de todo o método de Jessop, e como Mahon ${ }^{5}$ (1991) coloca, permite ao autor um dialogo diferenciado com outras abordagens teóricas.

\section{A abordagem estratégico-relacional e conceitos de economia e política}

Enquanto na parte anterior buscamos destacar o papel da lógica simples / complexo dentro da teoria de Bob Jessop, essa segunda parte busca tratar de outra diferença da teoria desse autor em relação à teoria poulantziana; abordaremos a crítica de Jessop sobre perspectiva funcionalista-estruturalista, e qual o conjunto conceitual desenvolvido por ele diante dessa crítica.

Essa crítica é bem evidente quando Jessop formula os conceitos econômicos de forma-valor e de estratégias de acumulação:

"A forma-valor é a relação social fundamental que define a matriz do desenvolvimento capitalista. Ela compreende um número de elementos interconectados que estão ligados organicamente como momentos diferentes na reprodução total da relação-capital. (...) Estes elementos interconectados da forma-valor definem os parâmetros nos quais a acumulação pode ocorrer e também delimitam os tipos de crises econômicas que podem se desenvolver no interior do capitalismo" (JESSOP, 2007, p.102-103).

${ }^{5}$ Aqui trato da citação já feita em nosso trabalho durante a discussão de Jessop e Poulantzas.

144 Bob Jessop e a abordagem relacional-estratégica 
A forma-valor, portanto, remete a uma dimensão mais estrutural e abstrata da realidade econômica. A crítica que Jessop faz ao funcionalismo e estruturalismo não é o de negar essa dimensão enquanto válida analiticamente, mas sim que a realidade concreta "acumulação de capital" não pode ser explicada apenas pelos parâmetros estabelecidos estruturalmente. Embora a "forma-valor" defina os parâmetros básicos do capitalismo, ela sozinha é incapaz de guiar uma análise da dinâmica e da natureza desse sistema social. (JESSOP, 2007, p.104).

A dinâmica e a natureza do capitalismo estão em operação dentro da realidade histórica de luta de classes. Através dessa luta é que as classes, diante desses parâmetros anteriores, definem "estratégias de acumulação". Estas seriam:

"Uma 'estratégia de acumulação' define um 'modelo de crescimento' econômico específico completo com suas diversas precondições extraeconômicas e delineia a estratégia geral apropriada para a sua realização." (JESSOP, 2007, p.105).

O que Jessop destaca é que os determinantes estruturais não são capazes de definir um modelo a ser aplicado praticamente, porque eles são parâmetros abstratos que não possuem entre si uma coordenação muito rígida; é necessário, para que a acumulação de capital realmente se realize, um "modelo" econômico que seja capaz de coordenar adequadamente esses determinantes, tendo em conta o momento histórico de luta de classes especifico.

A crítica de Jessop ao estruturalismo é justamente a afirmação de que as estruturas não possuem o poder explicativo que essa corrente teórica antes lhes atribuíam. As estruturas são importantes, mas uma análise social necessita perceber como os agentes sociais se relacionam com essas estruturas e formulam estratégias para o funcionamento dessas estruturas e também para a sua transformação.

A crítica ao funcionalismo é um desdobramento dessas conclusões econômicas diante da perspectiva de que o Estado possuiria a função de auxiliar a reprodução do capital. 
Bem, se o autor já concluiu que não existe uma única forma de reprodução do capital, mas sim várias possibilidades que são escolhidas não no plano estrutural, mas sim no da agência, a afirmação de que a função do Estado é auxiliar a reprodução do capital se torna uma afirmação vazia de conteúdo. O Estado não poderia ter suas estruturas entendidas pela sua função, já que esta seria variável de acordo com as estratégias de acumulação presentes na esfera econômica. As estruturas do Estado passam a ser analisadas por Jessop através do conceito de forma-Estado, em clara analogia com a forma-valor.

A forma-Estado também seria composta por elementos interconectados que serviriam como matriz para as relações políticas; como o próprio conceito indica, se refere aos aspectos formais do Estado. Jessop define como o mais importante desses aspectos a particularização do Estado, ou a separação institucional deste do circuito do capital, e também como elementos adicionais de análise as formas de representação, de intervenção e de articulação (JESSOP, 2007). Sobre a separação entre a forma-valor e a forma-Estado, Jessop (2007) destaca: “(...) é óbvio que a sua separação institucional permite um deslocamento entre as atividades do Estado e as necessidades do capital. (...) Isso se deve ao fato de que tanto a forma-valor do MPC quanto a sua forma estatal particularizada são indeterminadas em certos aspectos, de maneira que qualquer correspondência ou deslocamentos entre elas ou entre seus conteúdos substanciais dependerão de muitos fatores além dos mecanismos puramente formais."(JESSOP, 2007, p.118)

Essa indeterminação no nível estrutural cria um impedimento de relacionarmos a forma-Estado e a forma-valor apenas estruturalmente. Essa conclusão entra em conflito direto com diversas concepções de Poulantzas utilizadas na abordagem regional das instâncias. A relação entre estas, e conceitos como autonomia relativa, ou dominância do econômico em última instância, são colocados em xeque se entendidos apenas como relações entre estruturas sociais. Como Block destaca:"Jessop debate fortemente contra o uso d'a autonomia relativa do Estado' ou 'determinação em última instância' enquanto princípios explicativos"(BLOCK, 1991, p.872). Assim, para uma análise adequada 
do Estado, além da dimensão formal, torna-se necessário o estudo dos seus aspectos mais substantivos.

"Além destes aspectos formais do sistema estatal, devemos também examinar seus aspectos substantivos. Além das politicas específicas implementadas pelo aparato estatal, há duas determinações mais gerais: as bases sociais de apoio e oposição ao Estado e a natureza do 'projeto hegemônico' (se existente) ao redor do qual o exercício de poder estatal está centrado." (JESSOP, 2007, p.119).

Percebemos com o trecho citado que, por "aspectos substantivos do Estado", Jessop entende muito mais do que as políticas públicas concretamente implementadas, pois a realidade política de luta de classes, e os projetos que os atores políticos formulam sob circunstâncias históricas determinadas também fazem parte dessa substância. Essa perspectiva é fruto da adoção do conceito relacional de Estado de Poulantzas; a correlação de forças entre as classes sociais se condensa materialmente, formando aquilo que chamamos de Estado.

Essa análise substantiva consistiria, portanto, na análise de políticas públicas implementadas pelo Estado, na análise das forças políticas existentes na sociedade, e também na análise do que Jessop chama de "projeto hegemônico".

É esse último conceito que Jessop enfatiza mais. Seria necessário, para uma organização concreta politicamente de classe, a existência de uma liderança que fosse capaz de unir politicamente, ideologicamente e moralmente "diferentes forças com 'relevância de classe'", resolvendo concretamente a série de contradições existentes abstratamente (JESSOP, 2007, p.120)

Enquanto que a estratégia de acumulação envolve principalmente objetivos econômicos, o projeto hegemônico se baseia principalmente em objetivos extra-econômicos, mesmo que estes sejam "economicamente condicionados e economicamente relevantes" (JESSOP, 2007, p.120).

Assim sendo, percebemos que existe uma separação entre os conceitos econômicos e políticos de forma-valor e forma-Estado; e também de estratégia de acumulação e projeto hegemônico. Essa 
diferenciação é importante para não adotarmos uma perspectiva que enfatiza demasiadamente a relação estrutural entre a política e a economia, e também não nos restringirmos a uma análise dos fenômenos sociais que apenas aponta as interconexões imediatamente dadas entre economia e política.

Percebemos que a relação entre economia e política não é dada totalmente nem no plano estrutural e nem no plano concreto, mas só uma análise que transite entre essas duas dimensões pode ser capaz de avaliar corretamente qual seria o grau de independência e dependência entre essas duas esferas.

\section{Apontamentos finais}

A abordagem estratégico-relacional de Jessop deve ser entendida pelo contexto político que o marxismo vivia na época. A importância que o autor deu, em sua entrevista, ao "Thatcherismo" não foi colocada apenas como uma preocupação enquanto objeto de estudo; como ele mesmo coloca, essa preocupação política está inserida no subterrâneo de seu trabalho (JESSOP, 2002).

Esse "Thatcherismo", que representou a implementação das políticas neoliberais dentro da Inglaterra, deve ser entendido como uma variável que influiu na posição do marxismo enquanto corrente teórica dentro da academia. O marxismo, nesse contexto político, já não possui a mesma força que possuía na época em que Jessop tomou seus primeiros contatos com essa corrente teórica.

O que devemos entender é que ele desenvolveu grande parte de seu trabalho na década de 80, enfrentando adversários com uma força política dentro da academia muito maior que os adversários do marxismo da década de 70 .

Diante desse contexto acadêmico, de ascensão de perspectivas favoráveis ao direcionamento político neoliberal, o problema colocado ao marxismo foi justamente como criar um diálogo com as outras correntes teóricas que se opunham a essa linha política específica.

Nesse sentido é que podemos entender o porquê de Jessop ter utilizado a perspectiva relacional de Poulantzas. Essa perspectiva, se 
comparada com a abordagem regional das instâncias, seria muito mais flexível no diálogo com outras correntes teóricas; diálogo esse que estava colocado como questão política ao marxismo.

Percebemos assim como é contextualizada essa tendência de Jessop, identificada por Mahon (1991), ao diálogo com outras correntes teóricas. O problema do Estado, debatido nas correntes teóricas marxistas da década de 70 na forma de um confronto direto com outras perspectivas (para citar alguns exemplos, a oposição que Miliband (1972) faz ao pluralismo ao desenvolver sua concepção de Estado; ou a posição que Poulantzas (1971) faz ao historicismo e à teoria das elites), em Jessop passa a ser construído em um debate com o Institucionalismo.

Debater o Estado, em vez de significar uma negação de outras correntes teóricas, significou um diálogo com a corrente Institucionalista. Não que esse diálogo tenha sido construído sem críticas; essas críticas foram profundas e atingiram grande parte dos autores dessa corrente, mas a problemática do bring the state back in não foi negada, ao contrário, a abordagem relacional-estratégica buscou operar justamente no intuito de responder adequadamente esse problema.

Quando pensamos o conjunto conceitual marxista que está contido no livro "The Capitalist State" devemos considerar, portanto, um aparato conceitual que não se propõe negar outras correntes teóricas (como o "Estado na Sociedade Capitalista" de Miliband ou o "Poder Político e Classes Sociais" de Poulantzas), mas sim que abre espaço para outras formas de análise.

Esses apontamentos teóricos também possuem implicações políticas; essa forma diferenciada de se relacionar com as outras correntes teóricas também representou uma mudança sobre a concepção política do marxismo. Ao lado dessa abertura ao dialogo teórico também devemos entender o reposicionamento dos marxistas da época sobre temas como participação política da classe trabalhadora no Estado e também sobre democracia. Mas tal reflexão exige um trabalho que aprofunde não só o pensamento de Jessop, mas também do marxismo como um todo das décadas de 70 e 80. 


\section{Referências Bibliográficas}

BLOCK, Fred. Review: Bringing the State Back to Its Proper Place. In: Contemporary sociology. Vol. 20, No. 6. 1991.

JESSOP, Bob. Nicos Poulantzas: marxist theory and political strategy. London: Macmillan. 1985.

JESSOP, Bob. Institutional re(turns) and the strategic-relational approach. In: Environment and Planning A, v.33. 2001.

JESSOP, Bob. Globalização, regionalização, Mercado e o Estado: entrevista com Bob Jessop. In: Currículo sem fronteiras. v.2, n.2, 2002. Entrevista concedida a Ankara Mürekkep.

JESSOP, Bob. Estratégias de acumulação, formas estatais e projetos hegemônicos. In: Revista Idéias. Ano 14, (1/2). 2007.

JESSOP, Bob. The capitalist state: marxist theories and methods. New York: New York University Press. 1982

MAHON, Rianne. "Bringing" to "putting": The State in Late Twentieth-Century Social Theory. In: The canadian journal of sociology. Vol. 16, No. 2. 1991.

MILIBAND, Ralph. O Estado na Sociedade Capitalista. Rio de Janeiro, Zahar, 1972. 
POULANTZAS, Nicos. O estado, o poder, o socialismo. 4. Ed. Rio de Janeiro: Graal. 2000.

POULANTZAS, Nicos. Poder Político e classes sociais. Porto: Prtucalense. 1971.

POULANTZAS, Nicos. Classes sociais no capitalismo de hoje. Rio de Janeiro: Zahar. 1974. 
